\title{
Assessment of public health of production workers according to HRV
}

\author{
Anastasia Bashkireva ${ }^{1}$, Tatiana Bashkireva ${ }^{1, *}$, Alexander Severin ${ }^{2}$, Sergey Chibisov $^{2}$, \\ Natalia Fateeva $^{3}$, and Evgeniya Severina ${ }^{2}$ \\ ${ }^{1}$ Ryazan State University named after S.A. Yesenin, associate professor, st. Svobody, 46, 390000, \\ Ryazan, Russia \\ ${ }^{2}$ Peoples' Friendship University of Russia, st. Miklukho-Maklaya, 8, 117198, Moscow, Russia \\ ${ }^{3}$ Tyumen State University, st. Volodarsky, 6, 625003 Tyumen, Tyumen region, Russia
}

\begin{abstract}
The study of the social health of labour resources as human capital is an actual problem. In production workers, the vegetative status was studied in terms of heart rate variability. By the concept of autonomic reactivity A.M. Greenberg, the results of the study found that the vegetative status of male employees and workers differs. The employees performing functions related to the organization of the production process showed general sympathicotonia. Workers performing specific production tasks have a general sympathicotonia. The results of the study found that vegetative status makes it possible to assess the social health of production workers. In the context of the intensive introduction of neural networks and nanotechnology into industrial production, the number of employees will increase. As a result, there will be an increase in the likelihood of cardiorespiratory system diseases among this contingent of workers. This will entail the development of corrective programs for the prevention of diseases of the cardiovascular system, and the introduction of changes in the classifier of occupational diseases.
\end{abstract}

\section{Introduction}

The study of the social health of labour resources as human capital is an urgent problem. Human capital is the main driving force behind the socio-economic development of the world community. [1] T. Schultz and G. Becker considered human capital as a set of society's investments in vocational education, skills, ability to work, human health, providing social needs at different stages of development [2-4]. In modern conditions of intensive development of scientific and technological progress in all spheres of social life, special attention is pay to labour resources and their health: physical, medical, psychological, social. $[5,6]$ There is no consensus in the research on the definition of the concept of "social health" and its criteria. This is since it is studied by many sciences and determines its applied nature. [7] The health of a society depends on many factors.

Is it possible to assess the social health of a person and society by indicators of vegetative status? In labour physiology, much attention needs to pay to the state of the tone

\footnotetext{
* Corresponding author: bashkireva32@gmail.com
} 
of the vegetative system, as a reflection of the processes of adaptation to labour activity. [8, 9] It is known that the autonomic nervous system (autonomous), as the basis of automation and higher nervous activity, ensures the safety of health, the safety of the body from external influences, including labour activity. $[10,11]$ The concept of the vegetative status of a living system is understood as a set of adaptive reactions of the autonomic nervous system to the effect of a complex of stress factors of various natures, ensuring the vitality of the organism. [12] In establishing the vegetative status according to the indicators of heart rate variability, we used the concept of vegetative reactivity of A.M. Greenberg [13]. He identified seven types of autonomic reactivity [14, 15]: 1) general sympathicotonia; 2) partial sympathicotonia; 3) general vagotonia; 4) partial vagotonia; 5) mixed reaction; 6) general intense reaction; 7) general weak reaction. We assumed that the vegetative status allows us to model the dynamics of the prerequisites for diseases of the cardiovascular system of workers in production. In connection with the intensive development of scientific and technological progress in the new millennium, the efficiency of labour of workers and employees is changing.

This work aims to study the autonomic status in terms of heart rate variability in assessing the social health of male production workers.

\section{Materials and method}

We have studied the vegetative status according to the indicators of the analysis of heart rate variability. Of greatest interest is spectral analysis or analysis of slow hemodynamic fluctuations (PCA). Contribution to the study of ICG was made by G. Walter (1964), N.A. Aladzhalova (1979), N.P. Bekhte-reva (1980), M.V. Volkenstein (1981), S. Akselrod (1985), G.R. Ivanitskiy, V.I. Krinsky (1982), I. Richards (1988), H. Westerhoff (1992), D. emaitite, A.N. Fleischman (1991-2012) and others. Spectral analysis is one of the methods for studying physiological signals to obtain qualitative and quantitative characteristics of oscillatory processes. Following the literature data, the frequency ranges have a specific physiological content: HF is the vago-insular, and LF is the sympathetic branch of the baroreceptive reflex [16].

The Institute for the Implementation of New Medical Technologies "RAMENA" (Ryazan), together with the Institute of Biomedical Problems of the Russian Academy of Sciences (IBMP RAS, Moscow), have developed a specialized software and hardware complex "Varicard". It includes the ISCIM6.0 statistical complex, which was recommended by the Russian Ministry of Health as a standard tool for the study of heart rate variability in clinical practice [17], applied physiology and psychology. The methodology of heart rate variability using a non-invasive electrocardiographic system makes it possible to obtain information about the state of regulatory systems, which is contained in the functions of the "spread" of the duration of cardiointervals. The indicators were recorded in a 5-minute cardio interval using this complex.

The following indicators of the activity of the parasympathetic (RMSSD) and sympathetic (SDNN) links of the autonomic regulation of the circulatory system were studied; the power of spectra of frequency ranges (HF, LF), having a lognormal distribution. Correlation analysis made it possible to determine the vegetative status of the surveyed in assessing the social health of production workers. Our research has established that the above-listed HRV indicators are biological markers that affect human behaviour and his adaptive responses [18].

Workers and employees took part in our research various professions carrying out their labour activity in production. We examined 55 men, workers of various industries in 
Ryazan: Two groups were identified: employees $(n=29)$ workers $(n=26)$ of various occupations in the field of production at the age of 25-45 years.

\section{Results and discussion}

Correlation analysis showed a reliably high relationship between the RMSSD and HF ( $\mathrm{r}=$ 0.842 ; $\mathrm{P}<0.001)$ SDNN and HF $(\mathrm{r}=0.87$; $\mathrm{P}<0.001)$ indicators in men involved in organizing the production process. Also in this group, a reliably high relationship was found between RMSSD and LF $(r=0.738 ; \mathrm{P}<0.001)$, SDNN and LF $(\mathrm{r}=0.884 ; \mathrm{P}<0.001)$. By the concept of autonomic reactivity A.M. Grinberg, the vegetative status of male employees in production, performing functions related to the organization of the production process, revealed general sympathicotonia (Fig. 1). Our data indicate that the vago-insular branch enhances the sympathetic branch of the baroreceptive reflex, which contributes to the activation of the sympathetic link in controlling the regulation of the heart rhythm. It is known that sympathicotonia affects human behaviour. Researchers have linked vegetative status to mental health problems. The subjects noted the following signs of their condition: increased irritability, irascibility, thirst, increased sweating, frequent awakening during sleep.
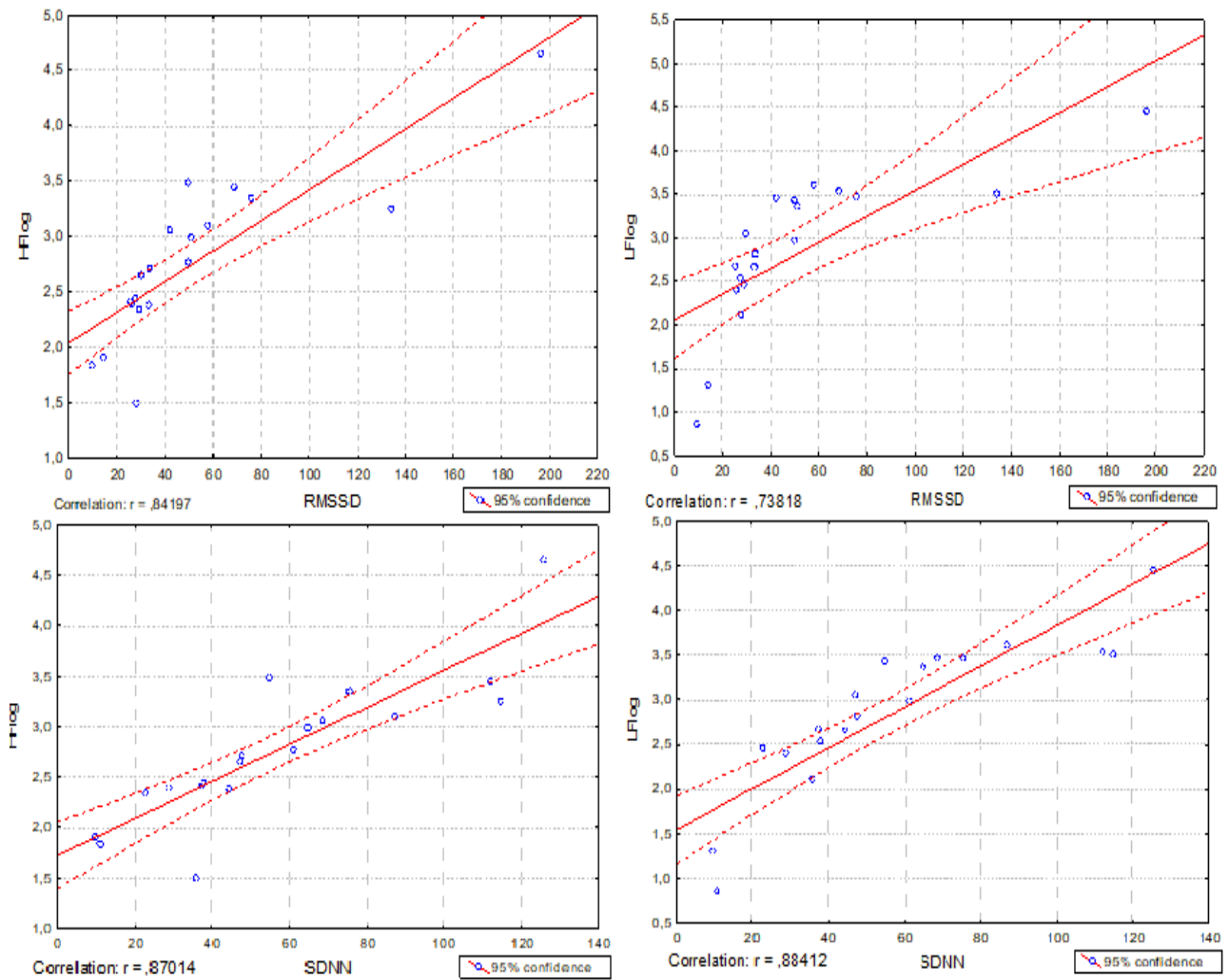

Fig. 1. The interrelation of vegetative indices RMSSD (1) and SDNN (2) with HFlog and LFlog in male employees under conditions of professional activity in production.

We can say that sympathicotonia affects the personal characteristics of employees and behaviour in the production process. The likelihood of a biased assessment of the new 
situation by employees when performing production tasks due to the human factor is high. In workers during the production process, a significant relationship was also revealed between RMSSD and HF $(\mathrm{r}=0.748 ; \mathrm{P}<0.001)$ SDNN and HF $(\mathrm{r}=0.709 ; \mathrm{P}<0.001)$. In this group, there is a significant relationship between RMSSD and LF $(r=0.5796 ; \mathrm{P}<0.01)$, SDNN and LF $(r=0.706 ; \mathrm{P}<0.001)$. Following the concept of autonomic reactivity A.M. Grinberg, the vegetative status of workers performing specific production tasks revealed general sympathicotonia (fig. 2).
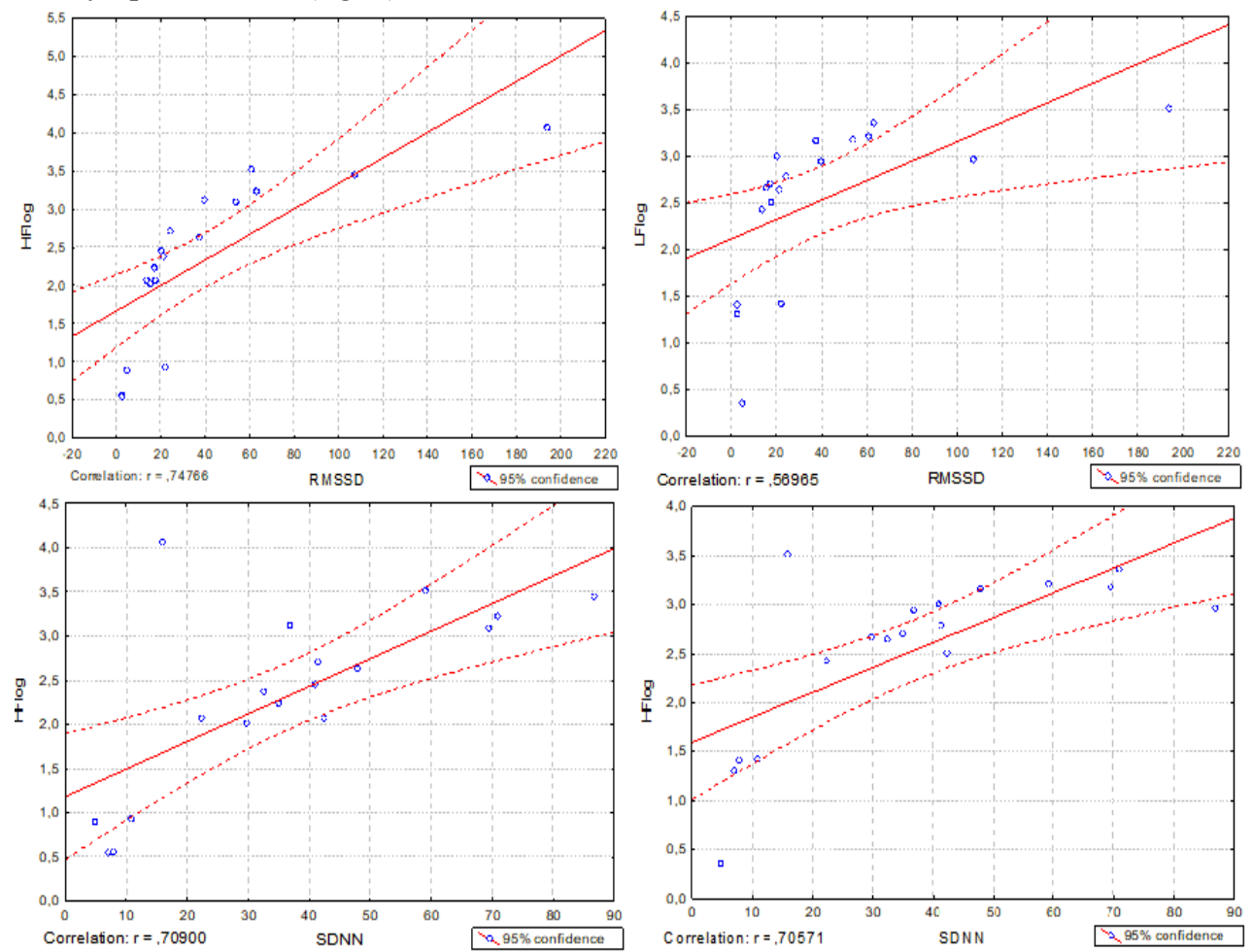

Fig. 2. The relationship of vegetative indicators RMSSD (1) and SDNN (2) with HFlog and LFlog in workers in the conditions of professional activity in production.

When questioning their condition, the workers named such signs as sleepiness, when performing monotonous actions; physical muscle tension; swelling and pain in the legs, fatigue when walking, thirst, increased sweating. The information obtained coincides with the medical indications noted in separate articles.

When analyzing the frequency-spectral components of employees and workers in professional activity, we observed a mutual transition of oscillations of the frequencyspectral components (HF, LF), which testifies to the adaptation processes.

Based on the correlation analysis, among employees and workers, we note the dominance of the sympathetic branch in the management of autonomic regulation of the heart rhythm of different levels.

The data we have obtained allow us to conclude that employees have preconditions for diseases of the cardiovascular system, and workers - chronic venous diseases. Consequently, there is a need to assess the social health of society through the prism of a particular individual's self-feeling and his vegetative status. 


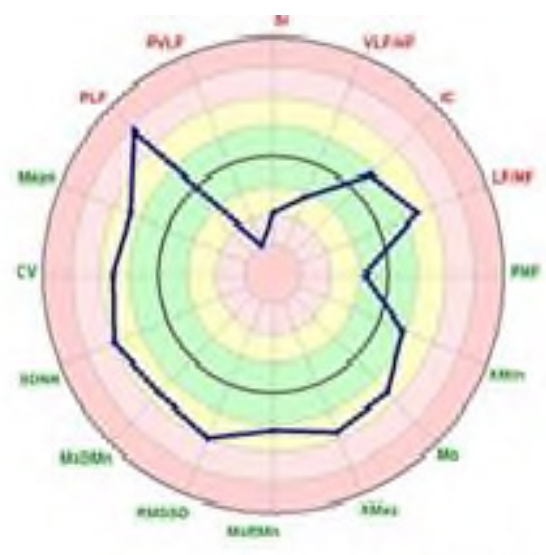

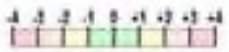

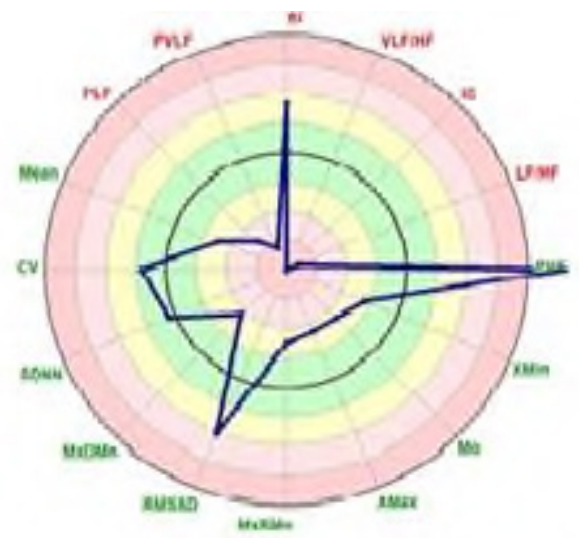

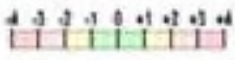

Fig. 3. Individual indicators of heart rate variability in an employee (1) and a worker (2) in the conditions of professional activity in the production.

\section{Conclusion}

The study of the vegetative status of production workers was carried out according to the indicators of heart rate variability. Following the concept of vegetative reactivity A.M. Greenberg, the results of the study found that the vegetative status of male employees and workers differs. General sympathicotonia was revealed in employees performing functions related to the organization of the production process. Workers performing specific production tasks also have general sympathicotonia.

During the study, also suggest that in the study of social health, it is advisable to take into account the vegetative status and consider it as a criterion that affects human behaviour and his adaptive responses. In the development of a system for the prevention of technogenic catastrophes and the human factor, regardless of production specialization, the vegetative status would be taken into account in assessing not only mental but also social health.

The result of the study we have established that the vegetative status allows us to assess the social health of production workers. In the context of the intensive introduction of neural networks and nanotechnology into industrial production, the number of employee operators will increase. As a result, there will be an increase in the likelihood of diseases of the cardio-respiratory system among this contingent of workers. This will entail the development of correction programs for the prevention of the cardiovascular system, and the introduction of changes in the classifier of occupational diseases.

\section{References}

1. M. Cavalcanti, S. Abreu, R. de Jesus, C. Andrade, Dealing with wicked problems in socio-ecological systems affected by industrial disasters: A framework for collaborative and adaptive governance, Science of The Total Environment 694, 133700 (2019) https://doi.org/10.1016/j.scitotenv.2019.133700 
2. H.I. Ballout, Career success: The effects of human capital, person-environment fit and organizational support, Journal of Managerial Psychology 22, 8, 741-765 (2007)

3. Yu.L. Eremkin, Impact of stress on psychological health, methods for measuring stress factors and the ability to cope with stress (Ryaz State University named after S.A. Yesenin, 2008)

4. S. Folkman, Manual for the ways of coping questionnaire (Palo Alto, CA Consulting Psychologist Press, 1988)

5. A. Campbell, N.O Neill, K. Higgins, Health and Social Care workers' perceptions of NPS use in Northern Ireland, International Journal of Drug Policy 40, 93-101 (2017)

6. S.S. Azizi, The impacts of workers' remittances on human capital and labor supply in developing countries, Economic Modelling 75, 377-396 (2018) https://doi.org/10.1016/j.econmod.2018.07.011

7. M. Fugate, Employability: A psychosocial construct, its dimensions, and application, Journal of Vocational Behavior 65, 1, 14-38 (2004)

8. J.H. Greenhaus, S. Parasuraman, W. Wormley, Effects of race on organizational experiences, job performance evaluations, and career outcomes, Academy of Management Journal 33, 64-86 (1990)

9. H. Mulder, O.T. Cate, R. Daalder, J. Berkvens, Building a competencybasedworkplace curriculum around entrustable professional activities: the case ofphysician assistant training, Med. Teach. 32(10) (2010) e453e9.https://doi.org/10.3109/0142159X.2010.51371

10. L. Gong, Y. Xiao, Ch. Jiang, Sh. Zheng, X. Fu, Seaport investments in capacity and natural disaster prevention, Transportation Research Part D: Transport and Environment 85, 102367 (2020) https://doi.org/10.1016/j.trd.2020.102367

11. Z.J. Wang, L.R. Long, Exploration of the relationship between human capital and career success in knowledge-based economy era, Foreign Economies and Management 27, 2, 18-23 (2005)

12. W.V. Ovalle, A. Martini, S. Tanguay, C. Carraccio, D.J. Schumacher, Implementing the Behavioral and Mental Health Entrustable Professional Activity: Insights for a Path Forward (Academic Pediatrics Available online 7 July 2020 In Press, Journal Preproof)

13. A.E. Agadzhanyan, T.V. Bashkireva, A.E. Severin, Gender differences in adaptive reactions in persons with varying degrees of intensity of professional activity, Russian scientific journal 3 (34), 305-309 (2013)

14. N.A. Agadzhanyan, T.E. Batotsyrenova, Yu.N. Semyonov, Ecological, physiological and ethnical features of human adaptation to various environmental conditions (Vladimir, Publishing house of the Vladim.Gos.un-t, 2010)

15. N.A. Aladzhalova, Psychophysiological aspects of infraslow rhythmic activity of the brain (Moscow: Nauka, 1979)

16. A.N. Fleishman, Slow fluctuations in hemodynamics, Theory, practical application in clinical medicine and prevention (Novosibirsk. The science. Sib. enterprise RAS, 1999)

17. C. Ivanov, Y. Ashkenazy, J.W. Kantelhardt, H.E. Stanley, Quantifying heartbeatdynamics by magnitude and sign correlations, Unsol. Probl. Noise Fluct. 665, 383-391(2003)

in:http://www.bgu.ac.il/ ashkena/Papers/AIP_Conf_Proc_2003_665_383.pdf 
18. L.A. Baikova, Theoretical foundations of the study of life-meaning and value orientations of production workers as a factor in the prevention of man-made disasters (Ryaz State University named after S.A. Yesenin, 2008) 